\title{
Libros de texto y nacional-catolicismo en las dictaduras salazarista y franquista
}

\author{
António Gomes Ferreira ${ }^{1}$ \\ ORCID: 0000-0002-3281-6819 \\ Erika González García ${ }^{2}$ \\ ORCID: 0000-0003-2465-7288
}

\section{Resumen}

Este artículo plantea cómo los manuales escolares forman parte del patrimonio históricoeducativo del sistema de educación, no solo por tratarse de objetos que muestran la memoria de los escolares, sino por ser un recurso imprescindible para el estudio de la cultura escolar de cualquier país. Conscientes de que los libros de texto han sido portadores de la cultura dominante de un período histórico y sometidos a regulaciones tanto políticas como religiosas, el objetivo de este trabajo es, en primer lugar, reflexionar sobre el tratamiento que se ha dado en ellos a dos pilares básicos como fueron la política y la religión, durante la dictadura de Salazar y la de Franco; y, en segundo lugar, analizar el contenido discursivo de los manuales, de los ejercicios y de las imágenes incluidas en ellos, que nos permitirá interpretar también el contexto socioeconómico y el papel otorgado a la familia y a las mujeres en un marco dictatorial. Tomaremos como referencia los libros de texto más utilizados por los escolares en las escuelas portuguesas y españolas.

\section{Palabras clave}

Libros de texto - Cultura material - Franquismo - Estado Novo - Educación.

1- Universidade de Coimbra, Coimbra, Portugal. Contacto: antonio@fpce.uc.pt

2- Universidad de Granada, Granada, España. Contacto: erikag@ugr.es 


\section{Textbooks and national Catholicism in the dictatorships of Salazar and Franco*}

\section{Abstract}

This article examines how school textbooks are part of the historical-educational heritage of the education system, not only for their being objects which reflect the memory of the schools but also for their being an indispensable resource for the study of the school culture in any country. Aware that textbooks have been the guardians of the dominant culture of a given historical period and subjected to political as well as religious regulation, the objective of this work is, firstly, to reflect upon the treatment they received with respect to the two basic pillars of society that were politics and religion during the dictatorships of Salazar and Franco; and secondly, to analyse the discursive content of the books, the exercises, and the images included, which will allow us to also interpret the socioeconomic context and the role afforded to the family and to women in a dictatorial regime. As a reference, we shall take up those textbooks which were the most used by children in Portuguese and Spanish schools.

\section{Keywords}

Textbooks - Cultural material - Francoism - Estado Novo - Education.

\section{Introducción}

La generalización de la escuela en las sociedades contemporáneas no se debe a la mera generosidad filantrópica ni a un compromiso desinteresado con la educación de las masas. Independientemente de las manifestaciones de algunas personalidades muy sensibles a la relevancia de la educación, sigue una dinámica social que responde a intereses vinculados al desarrollo de actividades económicas y al aparato burocrático del Estado-nación. Incluso si, desde una edad muy temprana, algunas personas más ilustradas y más atentas a los procesos de desarrollo abogan por la conveniencia de asistir a la escuela, llevaría mucho tiempo la escolarización de toda la población infantil (BOTO, 1999). Se vuelve urgente cuando el Estado puede movilizar las voluntades y los recursos necesarios porque está en juego la afirmación del país en el contexto de la competitividad económica internacional y el proceso de civilización alineado con los principios de la modernidad (FERREIRA, 2005). Ocurre, sobre todo, cuando hay una conciencia de la élite en el poder de la necesidad de dominar la lectura como una condición de entrenamiento básico, como una forma de inculcar ideas y valores queridos por la sociedad. Ahora, el esfuerzo realizado por el Estado hacia la educación de las generaciones más jóvenes, especialmente a partir de la segunda mitad del siglo XIX, llevó a la escuela a convertirse en un instrumento ideológico al servicio del poder instituido y, por lo tanto, se organizó para transmitir las ideas más centrales y fuertes inherentes al régimen político. 
De hecho, en el siglo XX, el libro escolar no es un simple objeto utilizado esporádicamente en el aula. Es un dispositivo pedagógico-cultural relevante en el proceso escolar tradicional. Por supuesto, su materialidad condiciona su fuerza tanto por su mayor o menor singularidad en relación con la presencia editorial en la sociedad, como por su capacidad para sugerir al estudiante. Pero aquí estamos más interesados en verlo como un vehículo de información, conocimiento, valores, creencias, ideas, en el que la escuela debería trabajar. Por lo tanto, constituye un referente de una cultura, ya sea porque expone contenidos fundamentales en un espacio-tiempo, o porque difunde formas de leer el mundo. Si François Marie Gérard y Xavier Roegiers (1998) consideran el manual como un instrumento impreso, estructurado intencionalmente para inscribirse en un proceso de aprendizaje con el fin de mejorar su efectividad, entendemos que uno debe verlo como un objeto antropológico, porque puede abrirse a una comprensión de su significado, teniendo en cuenta, entre otras cosas, la articulación de sus contenidos con las preocupaciones ideológicas, científicas y metodológicas de quienes promovieron su producción.

El libro de texto escolar es mucho más antropológicamente interesante que el carácter desechable que se le da hoy día. Se puede ver, entre otros aspectos, como soporte para el conocimiento escolar y como vehículo para un sistema de valores, una ideología, una cultura, participando en el proceso de socialización y aculturación (CHOPPIN, 1992).

No hay duda de que el libro de texto es un soporte curricular a través del cual se transmite el conocimiento académico que las instituciones consideran pertinente. Además, el libro escolar es un reflejo de la sociedad que lo produce, en cuanto que en él se vehiculan valores, actitudes, estereotipos e ideologías que caracterizan la mentalidad dominante de una determinada época o, lo que es lo mismo, el imaginario colectivo que configura el currículum explícito y también el oculto. Los manuales escolares son pues, una conceptualización del mundo que los escribe y de la cultura que se los apropia (ESCOLANO, 2009). Estas representaciones comportan un sentido que es percibido como un acuerdo semántico por parte del grupo que los produce y los lee, entendiendo que las representaciones no son simples formas de expresión de un capital cultural, sino que también son parte de círculos de poder que sustentan una economía política (ESCOLANO, 2001). Además, los libros de texto han sido históricamente un producto cultural controlado por los poderes políticos que han regulado su uso (BEAS, 1999; GONZÁLEZ, 2005). Por estas razones, tanto los contenidos culturales, como el lenguaje y la iconografía de los manuales escolares han ocupado la atención preferente de numerosas investigaciones que se han preocupado por desvelar la ideología que subyace en ellos.

Mirando a través de la Historia de la Educación tanto en Portugal como en España, vemos que en los mismos países se conocía el mismo sentido de la evolución de la producción / difusión del manual escolar que en otros países europeos. Ha pasado de ser un objeto raro, inaccesible, incipiente técnica y estéticamente, de uso colectivo, a un objeto más común, individual y cada vez más atractivo. Esto se debió, obviamente, a la combinación de varias condiciones, entre las cuales se encuentran el desarrollo de tecnologías para la producción de libros y la expansión de la población escolar.

Con respecto a los contenidos, considerando tanto lo explícito como lo implícito, podemos admitir que el manual de educación primaria, resultante del marco de luces, 
se identificó con la escuela como método, disciplina y, más tarde, como enciclopedia, en la que se condensaron todas las asignaturas indispensables para el conocimiento (MAGALHÃES, 1999). Sin embargo, a finales del siglo XIX y en las primeras décadas del siglo siguiente, hubo desacuerdos, motivados por diferentes concepciones de la educación. Además de los manuales muy antiguos, se agregaron otros con la influencia de las ideas novistas de la escuela que tratarán de estructurar el razonamiento, dando espacio para la profundización del conocimiento, utilizando libros escolares más específicos. Con la consolidación del régimen autoritario en Portugal, conocido como Estado Novo, el manual sería la llave maestra para una iniciación en una cultura primaria, reforzada por la introducción del libro único. Como bien señaló Justino Magalhães (2006), la superposición entre instrucción, escolaridad y educación, en las primeras décadas del Estado Novo, en una lógica básica y minimalista de la enseñanza primaria, convirtió el manual escolar en un solo libro y en una antropología básica. El manual escolar ordenó y permitió la interiorización de una visión sobre el mundo.

Al contrario de lo que sucedió en Portugal, la implantación del libro de texto único en España fue efímera. Por Orden de 11 de abril de 1938 (ESPAÑA, 1938) del Ministerio de Educación Nacional, en su artículo primero se encarga al Instituto de España la redacción y edición de textos destinados a la enseñanza primaria y "[...] que serán impuestos por el Estado con carácter obligatorio, así para la enseñanza pública como para la privada” (ESPAÑA, 1938, p. 6795). Más tarde se autoriza la venta y uso de determinados libros de texto, previamente censurados, para no causar graves daños a la industria editorial. En España, el franquismo no instauró el libro de texto único, pero sí impuso una censura previa, "[...] fue un producto cultural sujeto a control de los contenidos que transmitía y los valores que se reflejaban en su imaginario que en ellos se manifestaba." (ESCOLANO, 2006, p. 329). Como afirma Manuel de Puelles (1998), de lo que no hay la menor duda es que tanto el currículum como los libros de texto de enseñanza primaria y secundaria se sometieron a un control ideológico tanto desde el punto de vista político, como del religioso.

El objetivo de esta investigación es, en primer lugar, reflexionar sobre el tratamiento que se ha dado en ellos a dos pilares básicos como fueron la política y la religión, durante la dictadura de Salazar y la de Franco; en segundo lugar, analizar el contenido discursivo de los manuales, de los ejercicios y de las imágenes incluidas en ellos. Sobre ellos se intenta construir una identidad nacionalista basada en el desarrollo de vínculos con la tierra y con el mundo rural, con el pasado histórico forjado con mitos, héroes y leyendas, con la cultura religiosa y con un modelo de familia patriarcal-machista. Para realizar nuestra investigación, hemos analizado, como fuentes primarias, los libros de texto más utilizados por los escolares portugueses y españoles durante gran parte de los gobiernos salazarista y franquista.

\section{Una política autoritaria y una educación tradicional}

Nuestra investigación se enmarca en un contexto histórico-educativo que comenzó en torno a los años treinta bajo las dictaduras acontecidas en Portugal y España. Un régimen dictatorial encabezado en Portugal por Oliveira Salazar y en España por Francisco 
Franco, con una duración aproximada de cuarenta años. Se trata de una etapa muy larga que ha configurado en ciertos aspectos la educación que tenemos hoy en día. El modelo político-educativo de ambos países tiene en común una exaltación extrema de los valores culturales ordenados por la iglesia católica y los núcleos más conservadores de la sociedad. El centralismo, el autoritarismo, el conservadurismo, el culto a los principales líderes políticos, el dogmatismo, etc., son algunos de los rasgos característicos de este modelo totalitario. La síntesis de este modelo ideológico-cultural se centraba en la unión de los planteamientos del Estado y de la jerarquía eclesiástica, que actuaron como aparato ideológico de control, sobre todo de la educación.

En Portugal, los primeros años de la década de 1930 vieron el desmantelamiento de una sociedad liberal y la consolidación de un estado autoritario. Sin embargo, en enero de 1936, cuando se nombró a Carneiro Pacheco como ministro de educación pública, una política educativa consistente con el llamado régimen de Estado Novo avanzaría con confianza, consolidando un proyecto pedagógico y político de una escuela portuguesa y política que el programa nacional de resurgimiento debería servir (PEREIRA, 2014). Unos meses más tarde, la Asamblea Nacional aprobó una ley titulada Remodelación del Ministerio de Educación Pública, en la que se determinaron las bases principales que marcaron la dirección de la política a seguir por el Estado Novo en esta área (PORTUGAL,1936b). Desde la concepción que se imprimirá en la política educativa es significativo el cambio en el nombre del Ministerio de Instrucción Pública al Ministerio de Educación Nacional, que mostró la voluntad del régimen para mejorar los procesos de socialización y aculturación. La naturaleza ciertamente ideológica y autoritaria del régimen exigía necesariamente una estrategia doctrinal de educación. Por lo tanto, sirvió un proyecto doctrinal totalizador para la Sociedad Portuguesa, que dio forma a todos los niveles de la sociedad civil, inculcando una unidad político-ideológica, a través de instrumentos como la Escuela y las Organizaciones Juveniles (ROSAS, 2001).

Como es evidente, la generalización de la escolarización no implicaba una concepción igualitaria de la educación. Para la población en general, se entendió que una instrucción elemental basada en la lectura, la escritura y matemáticas, articulada con contenidos que deberían favorecer el apego a los valores del nacionalismo y el catolicismo, era suficiente. Las prácticas de adoctrinamiento son una constante en la dinámica educativa de la escuela del Estado Novo, que se puede ver tanto en la obligación de publicar ciertos pensamientos en las escuelas y en los libros escolares, como en la imposición del libro único en la organización física del espacio, en la elección del material didáctico y la atención al entorno educativo (NÓVOA, 2005).

La intención adoctrinadora de la educación escolar era muy explícita en la ley mencionada anteriormente, es decir, cuando, por ejemplo, las Bases IX y X examinan los programas y manuales, diciendo que "[...] las tablas de las asignaturas y los respectivos programas se revisarían en todos los grados de educación” (PORTUGAL, 1936b, p. 412 ) y que en los establecimientos educativos de todo el país, excluyendo la educación superior, habría un solo compendio para cada año o clase en las materias de Historia de Portugal, Historia general, Filosofía y Educación moral y cívica (PORTUGAL,1936b). No hay lugar para diferentes perspectivas, era imperativo formar las conciencias en la misma visión de 
lo que era el país y los valores que deberían gobernar la sociedad dirigida superiormente por Salazar. Por lo tanto, como señala Jorge do Ó (1999), la ideología ya no era sólo una expresión programática y debería impregnar las prácticas.

Muy indicativo de lo que se pretendía con la escolarización obligatoria fue la publicación del Decreto-ley (PORTUGAL, 1936a) con la indicación del plan de estudios que se enseñará a la educación primaria, donde era muy visible cuánto debería estar contenido en lo fundamental: "Lengua portuguesa (lectura, escritura y patria); Sistema aritmético y métrico; Moral; Educación física; Canto coral” (p. 1510). Aún más importante que la ideología que guió esta política educativa es la justificación presentada antes del alegato, donde se puede leer:

[...] que la educación primaria traicionaría su misión si continuara superponiendo un enciclopedismo racionalista estéril, fatal para la salud moral y física del niño, al ideal práctico y cristiano de enseñar bien a leer, escribir y contar, y a ejercer virtudes morales y un amor vivo por Portugal. (PORTUGAL, 1936a, p. 1510).

En vista de este propósito, no es sorprendente que el mencionado Decreto-ley se haya movido hacia la "[...] expiración inmediata de la aprobación oficial de todos los libros de educación primaria” (p. 1511), dejando espacio para una iniciativa, obviamente organizada y controlada por el Ministerio. Sin embargo, libros únicos solo aparecieron en los años cuarenta. Considerados en su totalidad, estos manuales para los primeros tres años de escolaridad son, sobre todo, profundamente ideológicos. Tanto en Portugal como en España, el catolicismo nacional incluía indiscriminadamente una ideología política y religiosa que debería inculcarse por todos los medios. Para lograr tal deseo, era importante que los manuales reflejaran esta posición oficial y, por lo tanto, lo mejor era poder producir el libro capaz de atraer a los niños y niñas y, al mismo tiempo, ser efectivo con respecto a la formación de una mentalidad nacionalista y católica.

El franquismo, desde el inicio de la guerra civil, implicó una erradicación de toda tolerancia política y religiosa que no fuese la católica y no sólo una exclusión, sino una represión de cualquier elemento disidente (ARNABAT, 2013). 0 se estaba con el Régimen o contra él; no había término medio. En consecuencia, no se permitía ningún tipo de discrepancia en materia política ni religiosa. En materia educativa existía un dirigismo educativo y cultural con el fin de preservar los valores morales establecidos. En este sentido, el papel asignado a la educación se consideraba fundamental. Como ha afirmado Manuel de Puelles (2010), se implanta una enseñanza confesional católica basada en tres premisas: enseñanza de acuerdo con la moral y el dogma católicos, enseñanza de la religión en todas las escuelas y el derecho de la Iglesia a la inspección de la enseñanza en todos los centros docentes. Se producirá una identificación total entre los valores religiosos integristas y los valores políticos nacionalistas, hasta los primeros años de la década de los años cincuenta; se consagrará el principio de subsidiariedad, es decir, el Estado se desvinculará de sus obligaciones respecto a la educación y la Iglesia será la fuerza social capacitada y legitimada para asumir esta función. En cuanto a la ideología política, se implantarán los valores tradicionales propugnados por el Movimiento Nacional. En consecuencia, tras la depuración 
de bibliotecas, libros de texto y sobre todo del profesorado, se implantará un férreo control ideológico religioso y político que los centros educativos se encargarían de desarrollar.

La Ley de Educación Primaria de 1945 (ESPAÑA, 1945) corrobora lo que hemos dicho anteriormente. En su preámbulo hace un recorrido histórico destacando los personajes ilustres que han destacado en el ámbito pedagógico y que nacieron en territorio hispánico: Quintiliano, San Isidoro de Sevilla, Raimundo Lulio, Elio Antonio de Nebrija, Juan Luis Vives, Ponce de León, San José de Calasanz y Andrés Manjón. Esa tradición pedagógica se quiebra, según dicho preámbulo, “[...] al advenir el mal llamado (siglo) de las luces, con su cortejo exótico de frivolidades, de racionalismos y de impiedad" (ESPAÑA, 1945, preámbulo, p. 385).

De ahí el empeño político del Movimiento Nacional y de la jerarquía católica, de restaurar una conciencia de los españoles al servicio de la Patria y de la religión. Por esta razón, esta Ley de 1945 invoca en su Preámbulo, entre los principios inspiradores, “[...] como el primero y más fundamental, el religioso" (1945, p. 386), la Escuela española ha de ser ante todo católica. Y además, la "Escuela en nuestra Patria ha de ser esencialmente española” (p. 386), inspirándose en el programa político del Movimiento Nacional. Ya en el desarrollo de la Ley, en el Capítulo II alude a los caracteres de la Educación primaria “[...] consubstancial con la tradición escolar española, se ajustará a los principios del Dogma y de la Moral católica y a las disposiciones del Derecho Canónico vigente” (p. 386). Igualmente, la Educación primaria tendrá como misión “[...] mediante una disciplina rigurosa, conseguir un espíritu nacional fuerte y unido e instalar en el alma de las futuras generaciones la alegría y el orgullo de la Patria, de acuerdo con las nomas del Movimiento y sus Organismos” (p. 388). Más adelante, el artículo quince define la escuela como “[...] comunidad activa de Maestros y escolares, instituida por la Familia, la Iglesia o el Estado, como órgano de la educación primaria, para la formación cristiana, patriótica e intelectual de la niñez española" (p. 389). El artículo treinta y siete establece los conocimientos que se debían impartir y que el alumnado debía adquirir. Se dividían en:

A) Instrumentales: Lectura interpretativa, Expresión gráfica (Escritura, Ortografía, Redacción y Dibujo) y el Cálculo.

B) Formativos, que "[...] constituyen la base de la educación moral e intelectual” (p. 394): formación religiosa, “[...] formación del espíritu nacional, en el que se incluyen también la Geografía e Historia, particularmente de España” (p. 394); la formación intelectual que comprende Lengua nacional y Matemática y por último, la educación física, que contiene Gimnasia, los Deportes y los Juegos dirigidos.

C) Complementarios, en los que incluye las Ciencias de la Naturaleza, las enseñanzas de carácter artístico (Música, Canto y Dibujo), o utilitario (Trabajos manuales, prácticas de taller y labores femeninas).

En el grupo de conocimientos formativos no se incluyen la Ciencias de la Naturaleza, pero sí la Geografía e Historia, porque podían ser fácilmente manipulables, tener un enfoque marcadamente nacionalista. Igualmente, la educación física se incluye también en este apartado porque su objetivo es "[...] formar una juventud fuerte, sana 
y disciplinada" y ser un instrumento de su "formación intelectual y moral" (Art. 10, p. 388). Dicho con otras palabras, la educación física al servicio de los intereses morales y patrióticos de la ciudadanía. Las enciclopedias, como el resto de los libros para primaria, reflejaban fielmente esta normativa.

Según Antonio Viñao “[...] tres rasgos definen la política inicial del libro y la edición escolar en el franquismo: el control ideológico, religioso y patriótico-político; la regulación diferenciada entre la enseñanza primaria y la media y el intento fracasado de imponer un texto único” (2015, p. 684-685). En España, no se llegó a implantar el libro de texto único. Los manuales que tuvieron mayor difusión en las escuelas fueron las enciclopedias, que se dividían, como sucedió también en Portugal, en tres grados. Cada uno de ellos, a su vez, se utilizaba en dos niveles educativos.

De la Enciclopedia Álvarez, "intuitiva, sintética y práctica” como decía en su portada, se llegaron a vender más de treinta millones de ejemplares y llegó a copar el 80\% del mercado de enciclopedias y libros para ese nivel de la enseñanza." (SANTOS, 2013, p. 13).

Es la poderosa razón por la que hemos decidido centrar nuestro estudio en esta enciclopedia.

\section{Contenido dominante en los libros de texto}

Con base en la matriz ideológica presente en los documentos legales sobre la educación de los gobiernos de Portugal y España y una apreciación general de los libros de lectura de educación obligatoria para el período de dictaduras encabezadas por António Oliveira Salazar y Francisco Franco, consideramos pertinente proceder a un análisis de su contenido para lograr una comprensión de los aspectos más relevantes a considerar en la formación de hombres y mujeres por parte de los regímenes en cuestión. Es importante ver cómo en ambos países fue posible proporcionar contenido que promoviera ideas queridas por los regímenes dictatoriales de la Península Ibérica y cómo los valores tradicionales de prejuicio transnacional se combinaron con figuras, lugares e historias que deberían contribuir a exacerbar los sentimientos nacionalistas. Sobre la base de este enfoque general de los documentos y libros mencionados anteriormente, la formación política, las creencias y prácticas religiosas, las cosmovisiones económico-sociales y el orden familiar surgieron como dimensiones de análisis.

\section{Una educación nacionalista y conservadora}

De cerca, no es difícil ver que los libros de lectura de este período buscan satisfacer un deseo político nacionalista conservador. En ellos se revela una pedagogía tradicional y autoritaria, lo que no significa que los referidos manuales no atiendan a lógicas emocionales susceptibles de provocar en el niño y en la niña la adhesión a narraciones queridas por la ideología de las dictaduras de Franco y Salazar. Los libros fueron diseñados no solo para pasar un contenido seleccionado para formar una visión del mundo consistente con la hiperbolización de las supuestas cualidades tradicionales de los respectivos países, sino 
también para permitir sentimientos que inculcaran apego a personalidades y momentos decisivos del desarrollo histórico de la nación, así como preceptos, valores y tradiciones derivados de la doctrina católica.

Al ser libros dedicados a diferentes años de escolaridad, fueron diseñados para cumplir con diferentes características y capacidades intelectuales. En Portugal, los libros destinados a los primeros dos años de escolarización buscaron temas más cercanos y familiares para los niños, las referencias espaciales se ampliaron cuando los libros pasaron a tercer y cuarto curso. En estos años de educación primaria, también es evidente la preocupación por reforzar el componente más relacionado con el imaginario de la identidad portuguesa, que aparece en los manuales publicados, ya sea antes de 1940 o después, numerosos textos hacen referencia a Portugal, tanto desde una perspectiva geográfica e histórica, como cultural. La historia portuguesa es ahora el objetivo de innumerables referencias y de aspectos característicos de algunas regiones portuguesas que tratan de construir la especificidad del país. Portugal se presenta como una nación única que, aunque con sede en el continente europeo, estaba principalmente orgullosa de la diversidad de sus regiones y recurrió a sus territorios en África y Asia (FERREIRA; BRITO, 2003).

Casi todas las referencias de carácter geográfico, histórico y cultural en los manuales de lectura de educación primaria se refieren a Portugal ubicado en el continente europeo o a sus colonias consideradas como Portugal en el extranjero. En el Portugal nacionalista de los años treinta y cuarenta, Europa tenía poco interés. Lo que había que enfatizar era lo que valoraba la dignidad de la nación y, por lo tanto, la insistencia en sus héroes y los territorios que aún poseía en Asia y África. A través de estos libros, la idea de un gran Portugal se logró a través de la gestión de los portugueses a lo largo del tiempo (imagen $n^{0} 1$ ).

\section{Imagen n. 1}

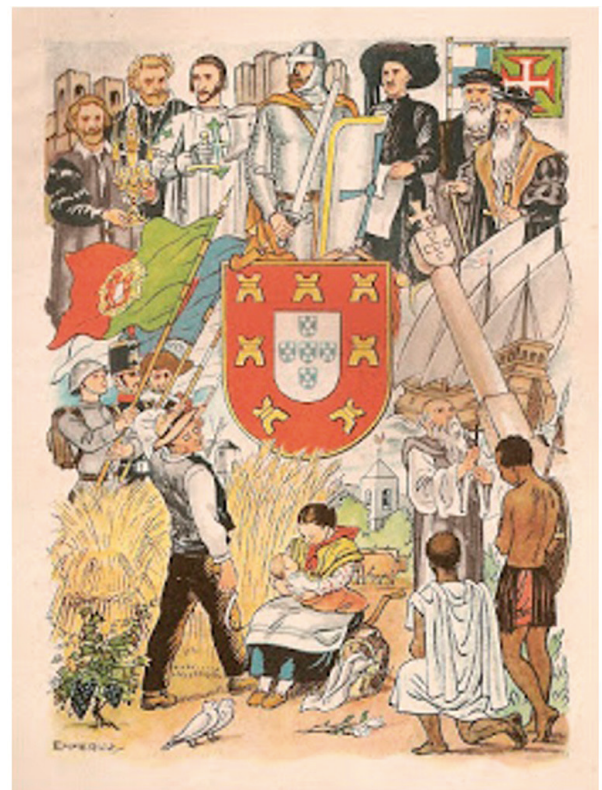

Fuente: O livro da terceira classe (1954) 
Portugal era visto como un país antiguo lleno de héroes: D. Alfonso Henriques, el primer rey, Nuno Álvares Pereira, un héroe de la independencia de Castilla, Infante D. Henrique, el iniciador de la expansión marítima, Vasco da Gama, el descubridor de la ruta marítima a la India, Alfonso de Albuquerque, valiente virrey en la India y, por supuesto, los líderes de la nación: el Presidente de la República y Salazar (O livro da terceira classe, 1954). Sin embargo, si la incitación patriótica es menos evidente en los libros de primer y segundo curso, no está completamente ausente de ellos. Los ejemplos más significativos se encuentran en los libros de los primeros cursos más aún porque, en cualquier caso, la forma en que se aborda el tema demuestra un claro propósito de impresionar a los niños. En uno, el texto, coronado por una ilustración de niños cantando, insta: «iArraial, oh portugueses, / Arraial, arraial, arraial! / Arraial, que está alerta / ¡Quién salvará a Portugal!» (O livro da primeira classe, s/f, p. 48); en otra, una página completa presenta un dibujo muy colorido donde dos niños colocados en la esquina inferior miran respetuosamente un mapa de Portugal que se encuentra sobre sus cabezas. De todos modos, mirando la mayoría de los manuales de lectura que fueron utilizados por los estudiantes que asistieron a los dos primeros cursos, está claro que Portugal, considerado en su totalidad y como una entidad soberana y simbólica, apenas era visible. Los libros de los años siguientes serían mucho más incisivos en esto (O livro da terceira classe, 1954, Livro de leitura para a $4^{a}$ classe, s/f).

En el caso español, aunque los tres volúmenes de la Enciclopedia Álvarez (ÁLVAREZ, 1962, 1964a, 1964b) estén estructurados en materias específicas relacionadas con la formación política, persisten, sin embargo, en todas las materias numerosas imágenes, alusiones a estereotipos, líderes, hechos de especial relevancia histórica y símbolos nacionales que de alguna forma son considerados pilares del patriotismo nacional. Así, por ejemplo, aparecen personajes míticos que han destacado por ser líderes militares y políticos como Felipe II, Pelayo y el Cid Campeador a los que se les equipara con Napoleón y a las que se suman figuras del Movimiento Nacional: Primo de Rivera, Franco, Calvo Sotelo o el General Moscardó.

Otro grupo de símbolos nacionales lo constituyen los conquistadores (Cristóbal Colón, Hernán Cortés y Juan Sebastián el Cano). También son objeto de estudio literatos considerados con renombre universal como es el caso de Miguel de Cervantes, pero otros, como los místicos Santa Teresa de Jesús o San Juan de la Cruz se les situaba también en un nivel destacado como máximos representantes de la literatura mística española que igualmente, por ser católicos, debían gozar de fama mundial. Caso parecido era el de Calderón de la Barca, insigne literato del siglo de oro español, que pese a escribir más de cien comedias y otras obras, se destacaba, sobre todo, por sus autos sacramentales. También se menciona a Félix María de Samaniego, escritor que destacó por sus fábulas de tono aleccionador y moralizantes que obviamente se ensalzaba de una manera desmesurada.

También se menciona a personajes ilustres nacidos en suelo peninsular pero que vivieron antes de que se constituyera la nación española, a los que se les honra como mitos hispanos: Viriato (en este caso, aunque nació en tierra portuguesa, se asume también como símbolo hispano), Séneca, Quintiliano, Trajano, Adriano y Teodosio. Tienen también un espacio curricular símbolos patrios como la bandera nacional, la bandera de Falange,

3- Se adopta el nombre de Enciclopedia Álvarez debido al nombre de su autor: Antonio Álvarez Pérez. 
la bandera Tradicionalista, el escudo nacional, la apropiación del yugo y las flechas como símbolos del Régimen y los himnos y cantos que alcanzan la categoría de nacionales como el Cara al sol o el himno de la legión. También se alude a otros símbolos que forman parte de la cultura inmaterial española como los toros, la paella o el baile de las sevillanas. Mención especial merecen los personajes y mitos religiosos como Santo Domingo de Guzmán o el Apóstol Santiago. Por último, se incluyen alusiones a fiestas políticas o religiosas que tienen como finalidad la celebración de algún evento o hecho considerado como seña de identidad española: 12 de octubre día de la Hispanidad, Día del caudillo, Día del dolor, Día de la Fe, Día de la madre, Semana Santa o el día del Papa.

\section{Imagen n. 2}

\section{Imagen n. 3}

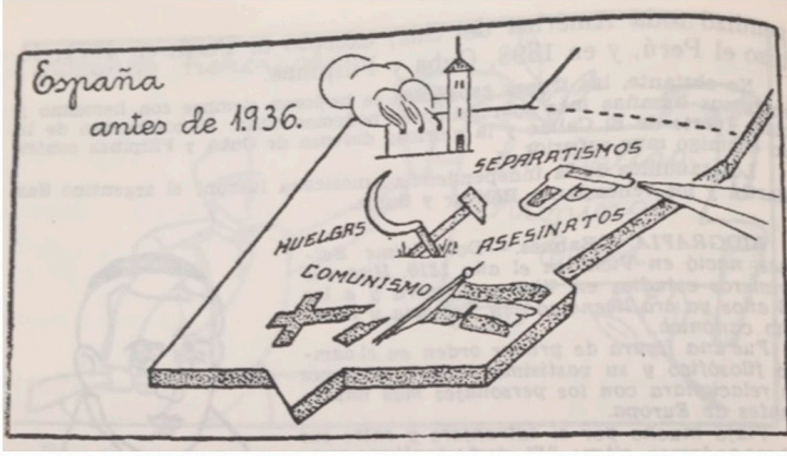

Fuente: Álvarez (1962, p. 382)

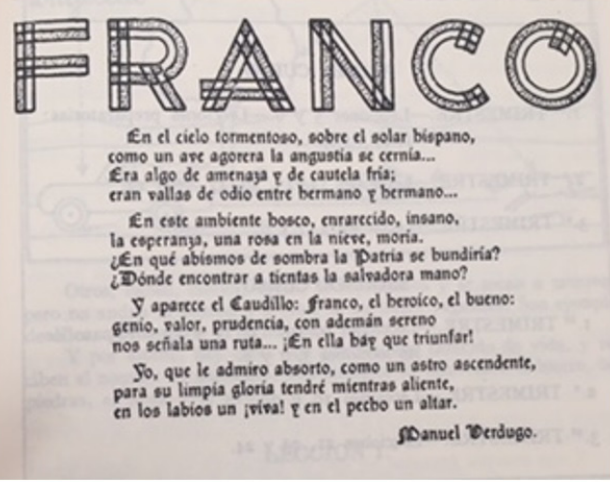

Fuente: Álvarez (1962, p. 389).

La imagen número 1 pretende transmitir una serie de estereotipos históricos que los golpistas utilizaron para justificar el denominado Alzamiento nacional y que se produjo el 18 de julio de 1936: incendio de iglesias y quema de conventos, asesinatos sin juicio previo predominando la ley del más fuerte, separatismo y quiebra de la unidad nacional, implantación de un régimen comunista y de su simbología, huelgas que llevaban a la deriva a la economía española, etc. Todo ello, habría justificado un Golpe de Estado de la denominada derecha española para restablecer la paz, el orden y la religión católica liderado por el dictador Caudillo Franco considerado héroe salvador como se señala en la imagen número 3.

\section{Formación religiosa: doctrina y rituales}

La religión fue uno de los elementos centrales en la configuración de la sociedad que pretendían los regímenes dictatoriales ibéricos. En Portugal, lo que es más evidente en los libros publicados después de los años cuarenta de aquellos similares a los utilizados durante la década de 1930 (PIMENTA; EVANGELISTA, 1933, 1934; VAIRINHO, 1935a, 1935b; CABREIRA; CABRAL, 1932) es el espacio dedicado a la religión. Cada uno de los tres libros tiene docenas de páginas de doctrina católica, que deberían funcionar como un catecismo, además de muchos otros con referencias a aspectos de naturaleza religiosa. 
En vista del espacio ocupado, no tenemos dudas de que el Estado Novo consideraba la religión católica como un haz estructurante de su ideología, pero queda por ver cómo los diferentes maestros vieron esta parte del catecismo (FERREIRA; BRITO, 2003).

\section{Imagen n. 4}

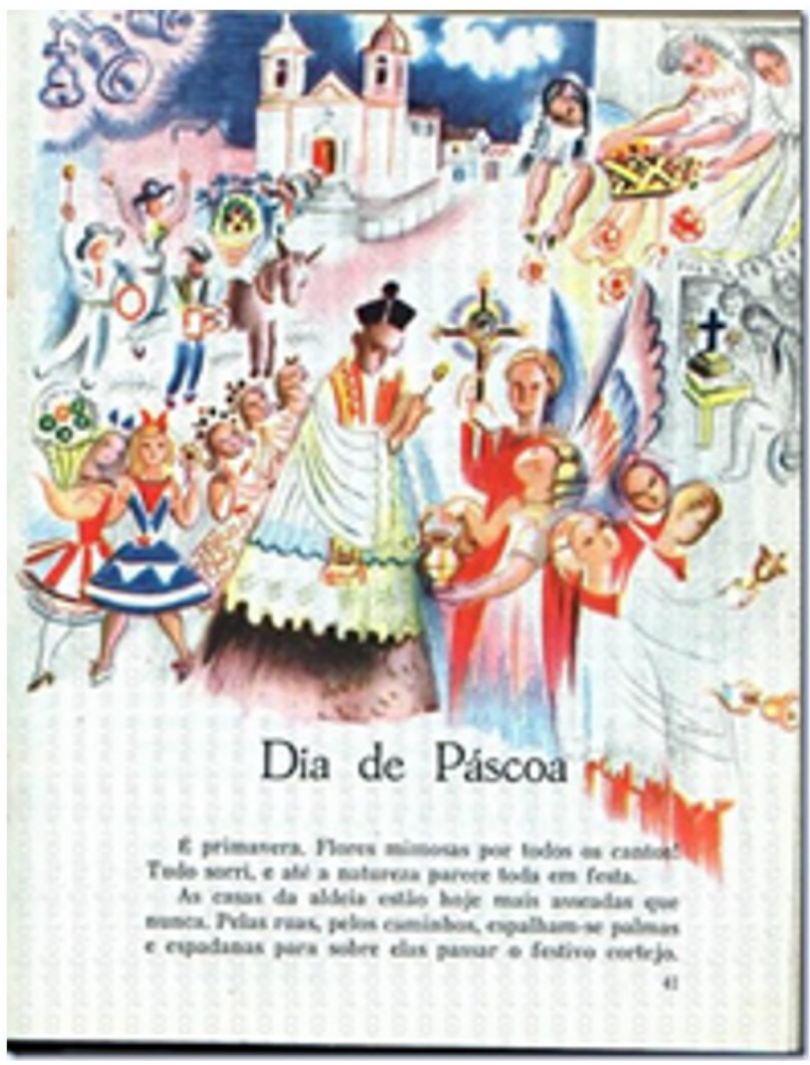

Fuente: O livro da segunda classe (1958).

Significativo es O livro da segunda classe (1958) que comienza exactamente con el texto Dios. La familia y su contexto son el tema principal, pero también se utilizan para hablar sobre rituales religiosos, Jesús, Ave María, caridad, día de Pascua (imagen n. 4). Es consensual y bastante evidente que la formación religiosa es uno de los pilares del nacional-catolicismo que define los regímenes encabezados por Franco y Salazar. Teniendo en cuenta los manuales en español, la religión se considera tan importante que subdivide en varios temas: Historia Sagrada, los Evangelios y la Religión. También hay una sección especial para conmemoraciones escolares de la cual hay abundantes festividades religiosas como el Domund, Corpus Christi, la exaltación de la cruz, el día del Papa, el festival de todos los santos, el día de los diferentes, Cristo Rey, Fiesta del Sagrado Corazón, durante el seminario o semana santa. Las figuras de los santos y las alusiones religiosas están presentes en todos los libros y cualquier lugar se considera adecuado para incluirlos. La formación religiosa está destinada a inculcar a través de imágenes, 
conferencias, nociones, ejercicios y diferentes tipos de conocimiento en diferentes tipos de letras, enfatizando en negrita los pensamientos éticos y la moral como por ejemplo: "Si quieres hacerlo, obedece a Iglesia", "Nuestra escuela es cristiana y está presidida por la Cruz", "No tememos nada en el mundo Jesús está con nosotros "o" Por las buenas almas, el fin del mundo y el mundo de la felicidad eterna” (1958, p. 341). Oraciones cortas, fáciles de memorizar y que los profesores comentaron y copiaron en los cuadernos de los alumnos. Subyace la idea de que estamos pasando por esta vida, que la Iglesia nos guía a la felicidad eterna y, por lo tanto, solo existen sus normas y que el sacrificio y la paz están realmente garantizados como se defendió en el pensamiento medieval.

\section{Entre el mundo rural y el urbano}

Observando los libros escolares correspondientes de Portugal y España, vemos que en ambos países se destaca el espacio dado a la diversidad de sus tierras y personas, la historia de la patria, los monumentos y las personalidades de referencia, las tradiciones y fábulas más importantes del imaginario portugués y español. En Portugal, los textos de los manuales que preceden a los libros únicos se analizan en su conjunto, existe cierta disparidad en términos de la dicotomía mundo rural/mundo urbano. Existen manuales que presentan una cantidad razonable de textos donde los elementos rurales prevalecen sobre casi ninguno relacionado directamente con el medio urbano y otros donde, aunque hay más textos que tratan sobre la realidad rural, también hay algunos relacionados con el medio urbano.

Del análisis queda claro que es en los libros únicos publicados desde los años cuarenta que las marcas relacionadas con el mundo rural son especialmente significativas. En O livro da primeira classe (s/f), esta realidad es evidente de inmediato en las cinco ilustraciones que acompañan la presentación de un número igual de vocales, pero también en las que se difunden a través de las lecciones dedicadas a otras letras. Hay muchas páginas con una o más figuras con paisajes o entornos rurales, mientras que las ilustraciones en las otras páginas rara vez nos presentan aspectos claramente urbanos. Además del bosque, las almendras, las fresas, las ovejas o el gusano de seda, tenemos el hombre que lleva la leña a la espalda, la mujer que toca el burro cargado de productos de la tierra o la ara, la campesina rodeada de herramientas agrícolas y varias aves.

En O livro da segunda classe (1958), a través de ilustraciones y textos, se favorece el medio rural, con muchos textos especialmente relacionados con la agricultura, el pastoreo y la silvicultura en lecciones como La cosecha, Los cereales, Los alcornoques, El granjero, El pastor. También en el $O$ livro da terceira classe (1954), adoptado como un libro único a principios de los años cincuenta, la afirmación de privilegiar al mundo rural con un énfasis especial en las actividades agrícolas es bastante evidente. Los pueblos, La vida en el campo, Las mondas, Los rebaños, Los riegos, Los segadores, La casa del granjero, son títulos que muestran esta importancia dada a las zonas rurales (imagen n. 5). Cabe señalar que los aspectos relacionados con la vida urbana apenas aparecen en este libro. Las ciudades fueron ignoradas en gran medida. De estos, se destacan los principales monumentos, que, sin embargo, se presentan por lo que representan para la Historia de la 
Nación, un tema al que el libro brinda un gran alivio y que lo distingue de los manuales destinados a años anteriores.

\section{Imagen n. $\mathbf{5}$}

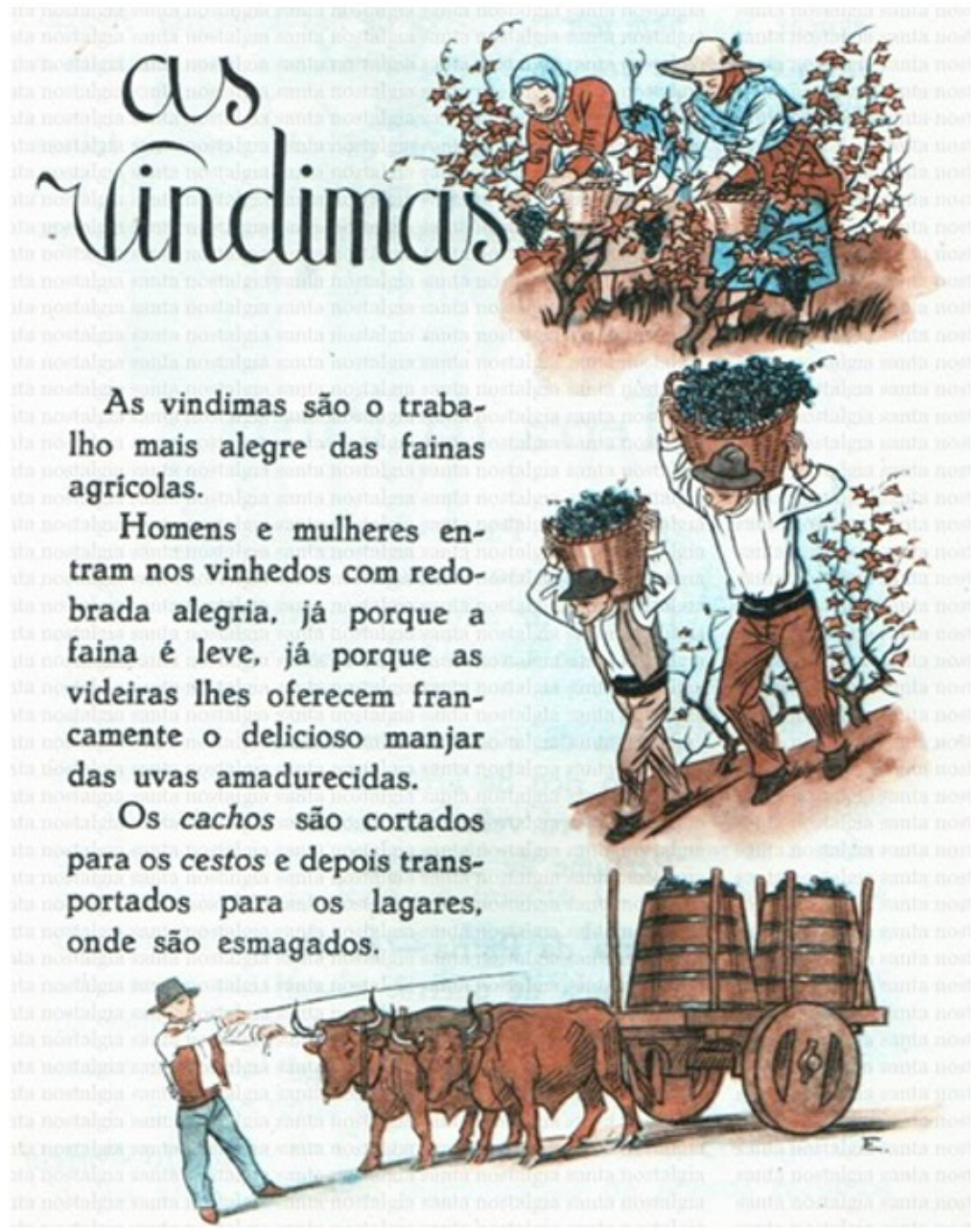

Fuente: Livro da terceira classe (1954).

El mapa de las regiones españolas se identifica con símbolos agrícolas como útiles agrícolas, casas rurales y profesiones (cabrero, mujer lechera, agricultor, etc.); las escasas referencias industriales son a la industria del automóvil, textil, zapatos y de cuchillos. El único país europeo que se menciona es Portugal y se acompaña de paisajes rurales. El mundo urbano se representa por medio de distintas fotografías de grandes ciudades que adquieren el rango de símbolos nacionales como la Plaza de España de Madrid o el Parque de Montjuich de Barcelona. 


\section{Imagen n. $\mathbf{6}$}

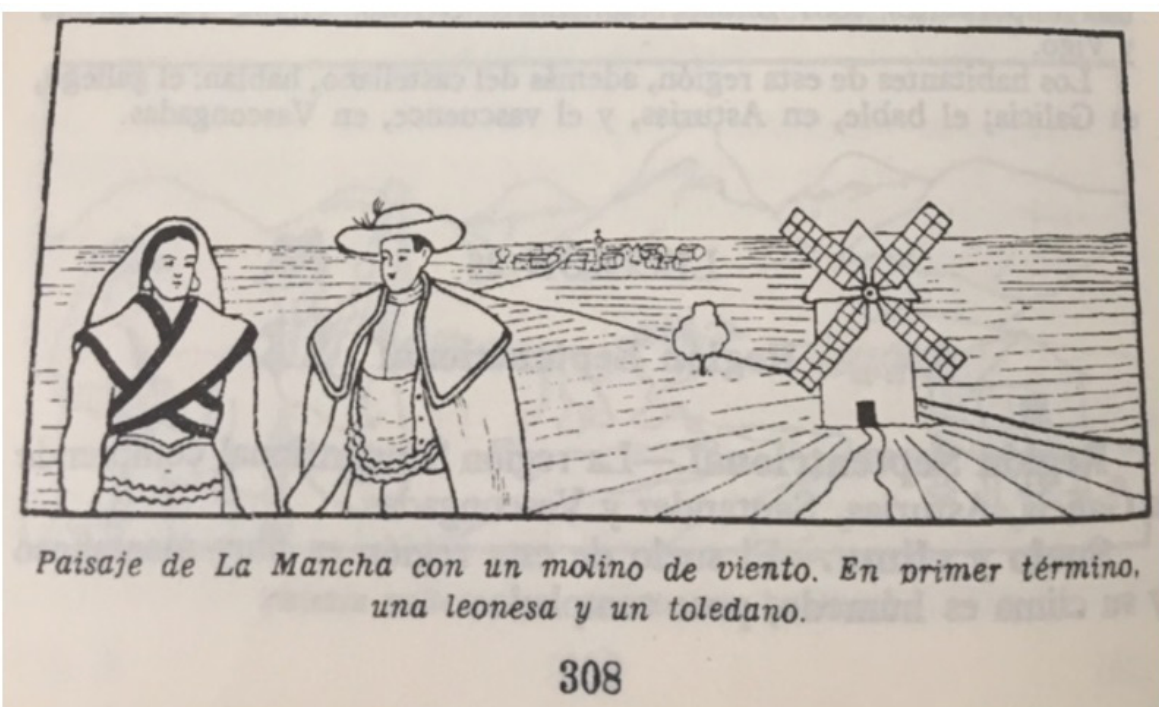

Fuente: Álvarez (1962, p. 308).

Tras la Guerra Civil, España se aisló del desarrollo económico que experimentaron otros países como Reino Unido, Francia, Alemania o Italia al mismo tiempo que rechazó cualquier incorporación de libertad o de liberalismo. Un sistema autárquico e intervencionista asfixiaba su economía y que en gran parte se salvó gracias a las remesas de los emigrantes, flujos de capital y divisas por turismo y por el aperturismo paulatino de la década de los años cincuenta.

El predominio económico del sector primario (GARCÍA DE CORTÁZAR; GONZÁLEZ, 2009) y la exaltación del mundo agrario frente al urbano tuvo su repercusión en el escaso acceso a la enseñanza secundaria que era elitista y seguía unas pautas marcadas por una fusión entre un catolicismo conservador y un nacionalismo franquista. Quienes estudiaban bachillerato (generalmente su acceso era a los 11 años) sólo utilizaban, como mucho, los dos primeros grados de la enciclopedia. El resto de la población escolar, raramente completaban los tres grados de la enciclopedia o pasaban directamente al mundo laboral en edades muy tempranas. En este sentido, la imagen 6, esquematiza el mundo rural utilizando un símbolo que Cervantes había universalizado en el Quijote, los molinos de viento, acompañado por los trajes regionales de una leonesa y un toledano, símbolos también de una pluralidad regional étnica folklórica.

La ruralidad fue claramente valorada por las dictaduras ibéricas, con gran énfasis en Portugal (ROSAS, 2001). Según Solé (2017), la ruralidad fue incluso el mito más frecuentemente tratado en los libros de la escuela primaria, y solo fue reemplazado por el mito del nuevo nacionalismo en el Livro da terceira classe. Como subraya el autor, "[...] la ruralidad y la pobreza honorable son dos de los mitos presentes en los libros únicos del Estado Novo con gran expresividad" (p. 107). En general, se asociaron con la vida simple, trabajadora y honesta vinculada con la familia católica tradicional. 


\section{La educación familiar y de género}

Los libros de los primeros dos años de escolaridad, que mostraban preocupaciones pedagógicas evidentes, tendían a centrarse en una realidad que pretendía ser más apropiada para la comprensión de los niños y, por lo tanto, se limitaban a presentar figuras y textos sobre objetos o entornos supuestamente familiares a estudiantes pequeños. Independientemente de pasar de palabras y figuras sueltas a textos cada vez menos cortos, los contenidos estaban vinculados a pequeñas historias de una infancia normal que tocaban aspectos moralizantes. Estos libros estaban llenos de padres, hijos, amigos, animales, casas y jardines, situaciones sugeridas de afecto, caridad, lealtad, obediencia consentida y autoridad parental. Las relaciones familiares y sociales se presentaron en marcos ideales y generosos. Las jerarquías parecían bien definidas pero delicadas y benévolas. Estos marcos obviamente estaban sujetos a las mujeres, sometidos a los mandatos superiores del padre o el esposo. La mujer tenía principalmente el papel de una esposa dedicada y una madre extrema, que se preocupaba por el buen nombre y el bienestar de la familia. Al ser considerados los principales trabajadores de la familia, quienes estaban a cargo de los primeros rudimentos de la educación, se les atribuyó fundamentalmente el papel de primeros educadores, primero guiando el carácter de los niños. "Como madre, en ella debemos contemplar el ejemplo vivo de los grandiosos compromisos de sus hijos, su consejero más íntimo y desinteresado, su maestra, la principal fuente de su amor, su educadora, el alma de su alma" (VAIRINHO, 1935a, p. 129-130), decía un texto, incluido en un libro de segundo curso.

Las mujeres en estos manuales de lectura son principalmente madres y amas de casa o, en el caso de realizar una actividad fuera del hogar, esto solo es cierto para los estratos sociales más bajos. Allí aparecen como lavanderas, costureras, panaderas o en la agricultura. La única excepción son los docentes, una profesión que, como hemos estado enfatizando, se sitúa en un plan de complementariedad a la educación iniciada con las madres. En cuanto a las madres, ya sea de la clase media o de campesinos simples, parecen amables, disponibles, buenas amas de casa, viviendo para sus hijos y esposo y haciendo todo lo posible para mantener la buena armonía del hogar (O livro da segunda clase, 1958).

Curiosamente, los manuales de los cursos tercero y cuarto, tomaron caminos muy diferentes. Con respecto a la imagen femenina, casi desaparece para dar lugar a un tema más vinculado al conocimiento de las profesiones, del funcionamiento del cuerpo, de los fenómenos naturales. Sin embargo, no dejaron de incluir textos con el objetivo claro de evitar que los valores mencionados anteriormente caigan en el olvido. Los padres aparecen como aquellos que deben ganarse la vida fuera del hogar para mantener a la familia, regresando a la casa al final de su trabajo. Las tareas domésticas no son necesariamente para ellos, quienes están a cargo de ellas son las mujeres.

Si todo iba de acuerdo con este orden transmitido por los manuales de lectura, no había nada que temer. La sociedad se mantendría en el camino seguido por sus antepasados, es decir, católicos, basados en la relación de benevolencia/servidumbre, formados por personas en el mismo idioma y la misma historia, personas orgullosas de sus tierras, tradiciones y costumbres y decididas a desempeñar su papel, según su sexo, edad 
y posición social. La familia era la institución que mejor podía socializar esta naturalidad de la desigualdad.

En el caso de la Enciclopedia Álvarez (ÁLVAREZ, 1964b), el mensaje es idéntico al que se transmitió en Portugal. La formación política estaba diferenciada por sexos. Los símbolos nacionales eran comunes, pero con roles distintos como se constata en el papel que se les asigna a las mujeres dentro de la Sección Femenina, uniforme, juegos y sus funciones sociales. Se inculca un modelo familiar muy patriarcal basado en una serie de principios que fomentan la convivencia, como el orden, higiene, cortesía, buenas relaciones, limpieza, amabilidad, ser respetuosas en el templo, etc. En resumen, se inculca un papel sumiso y obediente de las mujeres cuya misión es buscar la felicidad de esposo y de la familia aunque ello implique abnegación y su anulación como personas. Como se afirma en la Lección $1^{\text {a }}$ de La Familia (imagen n. 7).

[...] toda agrupación, para conseguir sus fines, necesita un jefe. El jefe de la familia es el padre. Como tal, trabaja y manda. Trabaja para dar ejemplo y procurar el bienestar de los demás miembros; manda, para que bajo su amorosa autoridad cada cual cumpla su misión: la madre administrando el hogar y los hijos preparándose para una vida moral y materialmente digna. (1964b, p. 624).

\section{Imagen $\mathbf{n} . \mathbf{7}$}

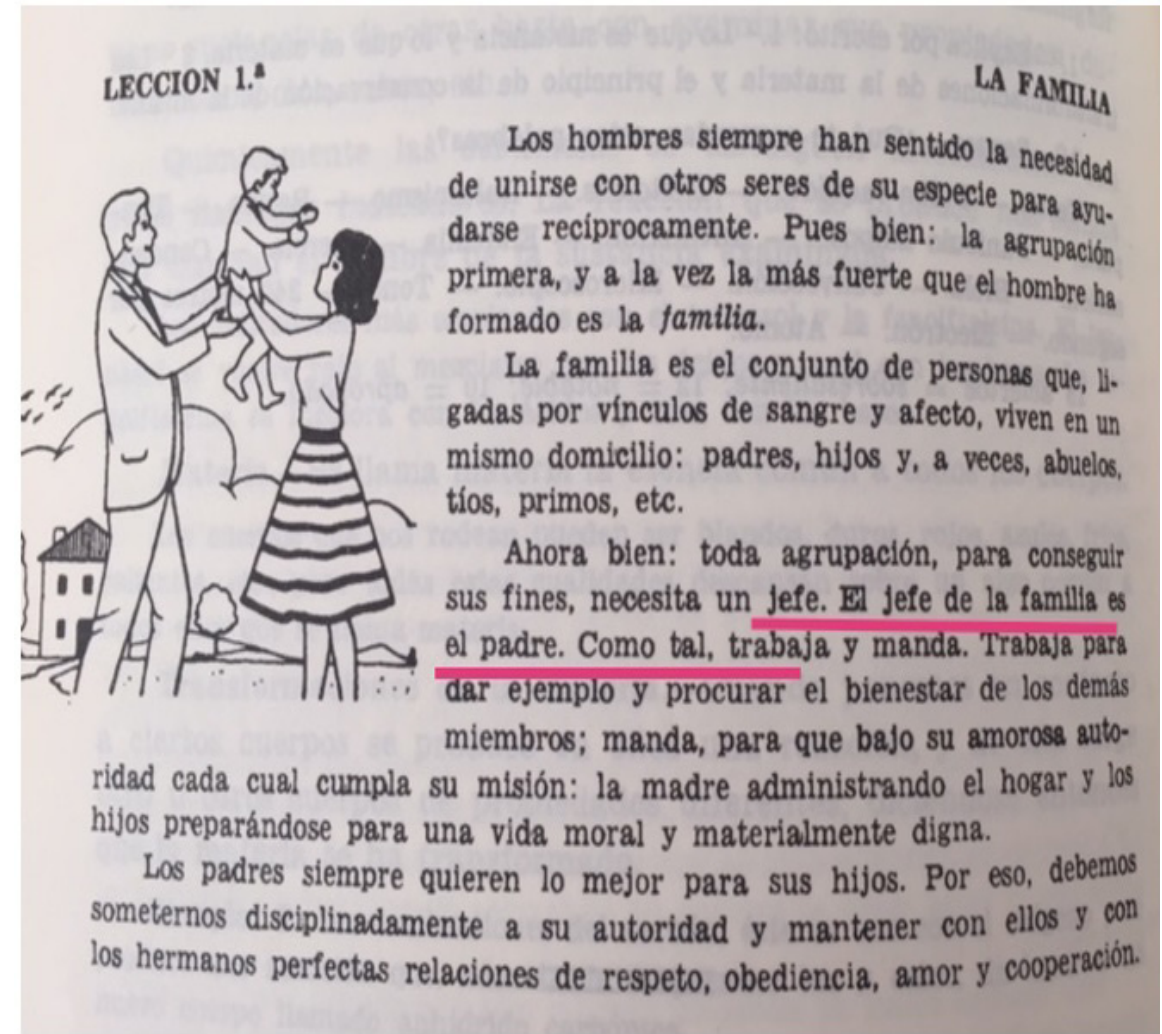

Fuente: Álvarez (1964b, p. 624). 
La Sección Femenina fue la organización encargada por el franquismo de formar políticamente a las mujeres y de capacitarlas profesionalmente, afianzando el modelo de feminidad católica y patriótica legitimado por el Régimen. Se afianzó un modelo patriarcal, con el apoyo de la Iglesia, diferenciando el rol de ambos sexos y potenciando una permanencia de las mujeres en el mundo rural fomentada por una formación agropecuaria, una consideración social, económica y cultural inferior a los hombres, el hogar como su espacio de predominante, el predominio de su misión maternal por encima de una autorrealización personal y el fomento de valores como la sumisión, la obediencia ciega al varón, asumir una cultura machista como un hecho natural, una ética con un predominio sexista represor, etc. (RAMOS, 2016).

\section{Conclusiones}

Los libros de texto de la escuela primaria publicados tanto en Portugal como en España, sirvieron a las generaciones escolares de los años 40-60, revelando que se pensaba que las escuelas portuguesas y españolas de esa época valoraban fundamentalmente los procesos de socialización y aculturación queridos por el régimen autoritario y conservador que dirigió el país por más de 40 años.

La identidad nacional ha exigido subordinación incondicional a los súbditos, fidelidad exclusiva, correspondiendo al Estado definirla, establecer límites entre sus ciudadanos y los otros. Cualquier identidad, para ser reconocida, tenía que tener el respaldo de la autoridad del Estado y de la jerarquía eclesiástica, que eran quienes configuraban la identidad nacional.

El retraso de la sociedad portuguesa y española durante esta época, afectaba a todos los ámbitos socioculturales y lógicamente también al sistema educativo. Éste era un sistema elitista, diseñado para la clase dominante más que para el conjunto de la población. Asimismo, se priorizaban los contenidos de tipo ideológico frente a los pedagógicos y científicos con el objetivo de perpetuar los principios patrióticos, morales y religiosos que establecía el régimen dominante. Como sabemos, la escuela ha sido y continúa siendo un lugar de interés tanto para los políticos como para la Iglesia y cuanto menor era la formación cultural del alumnado, más se percibe desde la distancia en el tiempo el interés por adoctrinarlo política y religiosamente.

El contexto de autarquía económica y cultural en el que vivían Portugal y España se reflejaba en los contenidos curriculares y en los libros de texto de Educación Primaria. En este sentido, observamos cómo los libros de texto dominantes en ambos países se cerraban a la cultura internacional, centrándose en la de sus países respectivos.

Teniendo en cuenta tanto el Preámbulo como el desarrollo de la Ley de 17 de julio de 1945 (ESPAÑA, 1945) y el contexto político y religioso que se vivía en los años 1940 y 1950, deducimos que, aunque en España no se llegó a implementar el libro de texto único, el modelo de escuela primaria, el currículum y la formación que se recibía en todos los centros sí era el mismo.

Con respecto al análisis de los libros de texto, aunque algunos de los valores transmitidos por estos manuales portugueses de la década de 1940 y siguientes no son 
muy diferentes de los presentados en medios similares en España, no hay duda de que se difundieron sistemáticamente durante un período de tiempo más largo, buscando interrumpir u obstaculizar los intentos de liberalización y modernización de los sectores más influenciados por el industrialismo y la cultura urbana. Si los libros publicados a lo largo de la década de 1930 ya estaban inclinados a incluir contenido valorado por el régimen encabezado por Oliveira Salazar y Francisco Franco, los libros que surgieron de la década de 1940 testifican claramente que la religión católica, el sentimiento patriótico y el mundo rural constituían bases principales en los que debía basarse la formación del pueblo. Partiendo de la verdad revelada por la doctrina católica, el carácter y los hechos de los héroes consagrados por la historia nacional, la belleza de las tierras y la laboriosa simplicidad de la vida en el país, combinada con una pedagogía tradicional, disciplinaria y autoritaria, la escuela en los países ibéricos de este período formaba personas empeñadas en el peso del pasado, el sacrificio de la obligación, la complacencia con la condición de vida, la sujeción jerárquica. Estos libros, que todavía marcan el ritmo de la vida escolar de los niños portugueses en los años sesenta, vinculan la imaginación del país con el pasado y evitan una pedagogía que prevea el futuro.

En relación a la formación política que se inculcaba, estaba basada, tanto en el aprendizaje y conocimiento de los principales mitos y símbolos nacionales, como la bandera, los himnos y los personajes considerados héroes, como en la ideología de los regímenes dictatoriales. Además, los libros de texto transmitían también de manera constante, ideas religiosas incluyendo oraciones, referentes religiosos, fragmentos bíblicos, etc.

El tratamiento que reciben niños y niñas en cuanto a la educación era diferente, no solo porque estaban divididos físicamente en las aulas, sino también por la formación que recibían en un contexto de desigualdades de género, en el que las funciones sociales y culturales eran diferentes para cada sexo. Aunque en las clases populares las mujeres trabajaban fuera, el hogar era tenido como su espacio propio, el lugar donde deberían asumir su misión maternal, sometidas a la obediencia del marido.

Los manuales analizados cumplen los mismos principios ideológicos católicos nacionalistas, conservadores y autoritarios. Si el régimen de Salazar parece haber asumido más claramente el papel principal del Estado en la configuración de los libros de texto, invirtiendo en la existencia de un libro único y permitiendo un aspecto gráfico más atractivo, la Enciclopedia Álvarez sigue la misma preocupación de impregnar de ideología las prácticas escolares. Si los manuales en español pretenden ser intuitivos, sintéticos y prácticos, los portugueses están en la misma línea pedagógica. Estos son incluso muy ilustrados y coloridos lo que los hace muy atractivos. La ideología debía ser aprendida por la memoria y por el sentimiento, interiorizada y sentida. Sin embargo, la misma ideología no evitó que los mitos, héroes, territorios, hazañas y símbolos fueran diferentes de un país a otro y con eso los libros de texto no favorecen los discursos de comprensión y afecto entre el portugués y el español. La exacerbación de los nacionalismos basado en lecturas selectivas y segregadas de la historia, en medio de la desconfianza política y económica que existía en ese momento, hizo difícil unir a los dos pueblos durante el período de las dictaduras de Salazar y de Franco. 


\section{Referencias}

ÁLVAREZ, Antonio. Enciclopedia intuitiva-sintética-práctica. Primer Grado. ed. 138. Valladolid: Miñón, 1964a. ÁLVAREZ, Antonio. Enciclopedia intuitiva-sintética-práctica. Segundo Grado. ed. 81. Valladolid: Miñón, 1962. ÁLVAREZ, Antonio. Enciclopedia intuitiva-sintética-práctica. Tercer Grado. ed. 108. Valladolid: Miñón, 1964b. ARNABAT, Ramón. La represión: el ADN del franquismo español. Cuadernos de Historia, Santiago de Chile, n. 39, p. 33-59, 2013.

BEAS, Miguel. Los libros de texto y las Comunidades Autónomas: una pesada Torre de Babel. Revista Complutense de Educación, Madrid, v. 10, n. 2, p. 29-52, 1999.

BOT0, Carlota. A escola primária como tema do debate político às vésperas da República. Revista Brasileira de História, São Paulo, v. 19, n. 38, p. 253-281, 1999.

CABREIRA, Estefânia; CABRAL, Oliveira. 0 bom amigo, livro de leitura para a primeira classe. Porto: Livraria Simões Lopes de Domingos Barreira, 1932.

CHOPPIN, Alain. Les manuels scolaires: histoire et actualité. Paris: Hachette, 1992.

ESCOLANO, Agustín. El libro escolar como espacio de memoria. In: OSSENBACH, Gabriela; SOMOZA, Miguel (dir.). Los manuales escolares como fuente para la historia de la educación en América Latina. Madrid: UNED, 2001. p. 35-46.

ESCOLANO, Agustín. El manual escolar y la cultura profesional de los docente. Tendencias Pedagógicas, Madrid, v. 14, p. 169-180, 2009.

ESCOLANO, Agustín. La codificación de la primera manualística. In: ESCOLANO, Agustín (dir.). Historia ilustrada de la escuela en España: dos siglos de perspectiva histórica. Madrid: Fundación Germán Sánchez Ruipérez, 2006. p. 219-240.

ESPAÑA. Ley n 385, de 17 de julio de 1945 sobre Educación Primaria. Boletín Oficial del Estado, Madrid, n. 199, p. 385-416, 18 jul. 1945.

ESPAÑA. Ley Orgánica 10/2002, de 23 de diciembre de 2002. Calidad de la Educación. Boletín Oficial del Estado, Madrid, n. 307, p. 45188-45220, 24 dic. 2002.

ESPAÑA. Orden de 11 de abril de 1938, Boletín Oficial del Estado, Madrid, n. 541, p. 6795, 15 abr. 1938.

FERREIRA, António Gomes. A difusão da escola e a afirmação da sociedade burguesa. Revista Brasileira de História da Educação, Campinas, v. 5, n. 9, jan./jun. p. 177-198, 2005.

FERREIRA, António Gomes; BRIT0, Ana Maria Parracho. A inevitável Espanha em narrativas de textos escolares. Eixo Atlántico, Vigo, n. 4, p. 211-230, 2003. 
GARCÍA DE CORTÁZAR, Fernando; GONZÁLEZ, José Manuel. Breve historia de España. Madrid: Alianza, 2009. GÉRARD, François-Marie; ROEGIERS, Xavier. Conceber e avaliar manuais escolares. Porto: Porto Editora, 1998. GONZÁLEZ, Erika. Del uso y abuso de los libros de texto: criterios de selección. Revista de Educación de la Universidad de Granada, Granada, v. 18, p. 269-281, 2005.

MAGALHÃES, Justino. 0 manual escolar no quadro da história cultural: para uma historiografia do manual escolar em Portugal. Sísifo, Lisboa, v. 1, n. 1, p. 5-14, 2006.

MAGALHÃES, Justino. Um apontamento para a história do manual escolar - entre a produção e a representação. In: CASTRO, Rui Riveira et al. (dir.). Manuais escolares, estatuto, funções, história: Actas do I Encontro Internacional sobre Manuais Escolares. Braga: Instituto de Educação e Psicologia: Universidade do Minho, 1999. p. 279-301.

NÓVOA, Antonio. Evidentemente: histórias da educação. Porto: Asa, 2005.

LIVRO de leitura para a $4^{\mathrm{a}}$ classe. Porto: Educação Nacional, [s.f].

O LIVRO da primeira classe. 6. ed. Porto: Educação Nacional, [s/f].

O LIVRO da segunda classe. 6. ed. Porto: Educação Nacional, 1958.

O LIVR0 da terceira classe, 2. ed. Porto: Figueirinhas, 1954.

Ó, Jorge Ramos do. Os anos de derro: 0 dispositivo cultural durante a "Política do Espírito", 1939-1949. Lisboa: Estampa, 1999.

PEREIRA, Maria Paula. A escola portuguesa ao serviço do Estado Novo: as lições de história de Portugal do Boletim do Ensino Primário Oficial e o projeto ideológico do salazarismo. Da Investigação às Práticas, Lisboa, v. 4, n. 1, p. 59-81, 2014.

PIMENTA, Romeu; EVANGELISTA, Domingos. Livro de leitura para a $1^{\text {a }}$ classe. 2. ed. Porto: Educação Nacional, 1934.

PIMENTA, Romeu; EVANGELISTA, Domingos. Livro de leitura para a 3ª classe. Porto: Educação Nacional, 1933.

PORTUGAL. Decreto-lei 27279, de 24 de novembro. Estabelece as bases do ensino primário. Diário do Governo, Lisboa, n. 276/1936, Série I, p. 1510-1511, 24 nov. 1936a.

PORTUGAL, Lei 1941, de 11 de abril de 1936. Estabelece as bases de organização do Ministério da Instrução Pública e altera a sua denominação para Ministério da Educação Nacional. Diário do Governo, Lisboa, n. 84/1936, Série I, p. 411-413, 11 abr. 1936b.

PUELLES, Manuel de. Educación e ideología en la España contemporánea. 5. ed. Madrid: Tecnos, 2010. 
PUELLES, Manuel de. La política del libro escolar: del franquismo a la restauración democrática. In: ESCOLANO, Agustín (dir.). Historia ilustrada del libro escolar en España: de la posguerra a la reforma educativa. Madrid: Fundación Germán Sánchez Ruipérez, 1998. p. 49-72.

RAMOS, Sara. Entre lo público y lo doméstico: capacitación profesional de las mujeres rurales en España (1940-1970). Madrid: Biblioteca Nueva, 2016.

ROSAS, Fernando. salazarismo e o homem novo: ensaio sobre o Estado Novo e a questão do totalitarismo. Análise Social, Lisboa, v. 35, n. 157, p. 1031-1054, 2001.

SANTOS, Mauricio. El pasado hasta casi el presente de los manuales escolares. In: BEAS, Miguel (ed.). Ciudadanías e identidades en los manuales escolares (1970-2012). Sevilla: Díada, 2013. p. 11-27.

SOLÉ, Gloria. A história nos manuais escolares do ensino primário em Portugal: representações sociais e a construção de identidade(s). Historia y Memoria de la Educación, Madrid, n. 6, p. 89-127, 2017 D0I: http://dx.doi.org/10.5944/hme.6.2017.17128

VAIRINHO, J. de Sousa. Leituras para crianças, $2^{a}$ classe. Lisboa: Paulo Guedes, 1935a.

VAIRINHO, J. de Sousa. Leituras para crianças, $3^{a}$ classe. Lisboa: Paulo Guedes, 1935b.

VIÑAO, Antonio. Capítulo XXIII. El libro escolar. In: MARTíNEZ, J. Antonio (dir.). Historia de la Edición en España (1939-1975). Madrid: Marcial Pons Historia, 2015. p. 681-698

Recibido en: 23.05.2020

Aprobado en: 21.07.2020

António Gomes Ferreira es doctor en Ciencias de la Educación. Director de la Faculdade de Psicologia e de Ciências da Educação da Universidade de Coimbra. Ha ocupado diferentes cargos como presidente de consejo científico, presidente de consejo Pedagógico y coordinador de doctorados en Ciencias de la Educación en la Universidade de Coimbra.

Erika González García es doctora en Pedagogía con mención internacional por la Universidad de Granada. Sus principales líneas de investigación están relacionadas con el estudio de la ciudadanía y las identidades en los recursos educativos. 